Cómo citar este artículo en MLA: Martín, F. “Especificidad histórica y crítica inmanente. Las teorías del capitalismo de Postone y Deleuze/Guattari”. Escritos 27.58 (2019): 95-118. doi: http://dx.doi.org/10.18566/escr.v27n58.a05

Fecha de recepción: 28.02 .2019

Fecha de aceptación: 06.05.2019

\title{
Especificidad histórica y crítica inmanente. Las teorías del capitalismo de Postone y Deleuze/Guattari
}

\author{
Historical Specificity and Immanent Critique: Postone's \\ and Deleuze/Guattari's Theories of Capitalism
}

\author{
Especificidade histórica e critica imanente. As teorias \\ do capitalismo de Postone e Deleuze/Guattari
}

\author{
Facundo Nahuel Martín ${ }^{1}$
}

1 Doctor en Filosofía por la Universidad de Buenos Aires, Argentina. Becario postdoctoral en CONICET (Argentina) y docente en la Universidad de Buenos Aires. Este artículo pertenece al proyecto de investigación UBACyT "La historia y los modos de experiencia del pasado", cuyo director es Daniel Brauer. Correo electrónico: facunahuel@gmail.com 


\title{
RESUMEN
}

Propongo un análisis comparativo de las teorías del capitalismo de Deleuze y Guattari en El Anti-Edipo y de Moishe Postone en Tiempo, trabajo y dominación social. Lo que Postone llama dominación abstracta es análogo a la axiomática capitalista de los autores franceses. En ambos libros se formulan teorías sobre la especificidad histórica del capitalismo, que a la vez hacen posible una crítica inmanente de esta forma social. Los autores coinciden en destacar los aspectos históricamente específicos del capitalismo, diferenciándolo de otras formas sociales. Asimismo, mantienen una relación parcialmente afirmativa con esta forma social, en la que se gestan ambigua o contradictoriamente posibilidades históricas emancipatorias. Trazaré, por lo tanto, un paralelismo (inexplorado en la bibliografía secundaria) entre la concepción de Postone de la dominación social abstracta y la axiomática capitalista de Deleuze y Guattari. Asimismo, intentaré mostrar que los tres autores (en las obras citadas) formulan una crítica del capitalismo que se basa en sus propios desarrollos históricos y sociales, procediendo de manera inmanente antes que con estándares normativos abstractos.

\section{Palabras clave:}

Capitalismo, Crítica inmanente, Deleuze y Guattari, Postone, Abstracción social, Axiomática social.

\begin{abstract}
The article presents a comparative analysis of the theories of capitalism of Gilles Deleuze and Felix Guattari's Anti-Oedipus and Moishe Postone's Time, Labor, and Social Domination. What Postone calls abstract domination is similar to the capitalist axiomatic of the French philosophers. These works introduce theories concerning the historical specificity of capitalism, which, at the same time, make possible an immanent critique of this particular social form. The authors of these works agree on highlighting the historically specific aspects of capitalism that make the latter different from other social forms. Likewise, they maintain a partially affirmative relation to this social form, in which contradictory historical emancipatory possibilities are developed. Therefore, the article draws a parallel (unexplored in the secondary sources) between Postone's idea of abstract social domination and Deleuze and Guattari's capitalist axiomatic. It also aims at showing that the three authors introduce a critique of capitalism, which is based on their own historical and social developments, and which work in an immanent way and not with abstract normative standards.
\end{abstract}

\section{Key Words:}

Capitalism, Immanent Critique, Deleuze, Postone, Social Abstraction, Social Axiomatic. 


\begin{abstract}
RESUMO
Proponho uma análise comparativa das teorias do capitalismo de Deleuze e Guattari no Anti-édipo e Moishe Postone em Tempo, trabalho e dominação social. O que Postone denomina dominação abstrata é análogo à axiomática capitalista dos autores franceses. Nos dois livros se formulam teorias sobre a especificidade histórica do capitalismo que, ao mesmo tempo, possibilitam uma crítica imanente dessa forma social. Os autores coincidem em salientar os aspetos historicamente específicos do capitalismo, ao diferenciá-lo de outras formas sociais.

Igualmente, mantêm uma relação parcialmente afirmativa com essa forma social, na qual se produzem ambígua ou contraditoriamente possibilidades históricas emancipatórias. Portanto, esboçarei um paralelismo (inexplorado na bibliografia secundária) entre a conceição de Postone da dominação social abstrata e a axiomática capitalista de Deleuze e Guattari. Além disso, tentarei mostrar que os três autores nas obras estudadas formulam uma crítica do capitalismo que se fundamenta em seus próprios desenvolvimentos históricos e sociais, ao proceder de um modo imanente, em lugar de usar padrões normativos abstratos.
\end{abstract}

Palavras chave:

capitalismo, crítica imanente, Deleuze, Postone, abstração social, axiomática social.

\title{
Introducción
}

En este artículo me propongo realizar un análisis comparativo de las teorías del capitalismo desarrolladas por Moishe Postone en Tiempo, trabajo y dominación social y por Deleuze y Guattari en El Anti-Edipo. Mi hipótesis de lectura es que existen analogías relevantes entre lo que Postone llama dominación social abstracta y lo que Deleuze y Guattari llaman axiomática capitalista. Ambos conceptos buscan reconstruir una misma realidad histórica, dando cuenta de los procesos sociales de la modernidad capitalista en términos de dos ontologías sociales diferentes, pero no necesariamente incomunicantes. Estos pensadores provienen de tradiciones marcadamente divergentes: Postone, formado en Frankfurt, se inscribe a la vez en el marxismo occidental y la teoría crítica de la sociedad. Reconstruye una lectura de Marx en clave de una crítica históricamente determinada de la sociedad capitalista. Deleuze y Guattari, por su parte, son asociados con el posestructuralismo francés. Recuperando la ontología spinoziana y la filosofía de Nietzsche, hacen una 
relectura original del pensamiento de Marx. Las tradiciones de pensamiento, los programas de investigación y los vocabularios filosóficos de Postone y de Deleuze y Guattari son marcadamente diferentes. Sin embargo, como trataré de explicar enseguida, es posible trazar paralelismos significativos entre sus teorías del capitalismo.

Postone entiende el surgimiento del capitalismo como una transformación de envergadura en la forma demediación social. Las sociedades no capitalistas hasta el momento se fundaron en relaciones sociales abiertas, basadas en vínculos de dependencia directa entre individuos o grupos. En cambio, en el capitalismo, las relaciones sociales aparecen como un cúmulo de compulsiones objetivadas, anónimas y abstractas. Entonces retroceden los vínculos organizados por la matriz tradicional y el propio trabajo (con sus categorías concomitantes: valor, mercancía, capital) pasa a estructurar la mediación social. Sobre esa base se gestan nuevas formas de independencia parcial para los particulares (por el retroceso relativo de la autoridad tradicional), así como una nueva forma de dominación basada en las propias coacciones impuestas a la acción por la dinámica automática y reificada del capital. El capital se caracteriza por la coexistencia ambigua, equívoca y contradictoria de una dinámica disolvente (de las relaciones sociales abiertas y la matriz tradicional), y una tendencia a la constricción permanente de esa misma dinámica por las coacciones impuestas a la acción, ahora por la propia lógica de la valorización.

Deleuze y Guattari, por su parte, comprenden la máquina civilizatoria capitalista en términos de una axiomática que presupone la desterritorialización de los movimientos de trabajadores y la decodificación de flujos de dinero. Al igual que Postone, enfatizan la especificidad histórica de la dinámica social abierta por el capitalismo. El socius territorial o despótico se basa en códigos que cortan y organizan los flujos en forma determinada. El capitalismo, en cambio, decodifica y desterritorializa los flujos, e instituye en su lugar la axiomática abstracta. Este modo de producción es doblemente disolvente. Lo es en relación con los movimientos de trabajo en cuanto se funda en el trabajo libre, desposeído de los medios de producción, pero también libre de las ataduras o coacciones tradicionales. Y también lo es en relación con las formas de codificación de flujos precapitalistas (lo que libera a la categoría de dinero para funcionar de modo autonomizado como capital). Este movimiento de disolución (de códigos y territorialidades), sin embargo, viene acompañado de un nuevo proceso de inscripción y restricción de la dinámica social. 
Los flujos que se inscriben en el socius son reorganizados bajo la axiomática del propio capital, que se pone como límite y marco de todo el proceso de decodificación y desterritorialización. La axiomática, en su carácter abstracto, es disolvente con respecto a los códigos tradicionales, pero no lo es con respecto a su propia lógica formal. Opera como la lógica fundamental de la sociedad capitalista, reemplazando con su dinámica abstracta a los códigos de las máquinas territoriales o despóticas. Además, la propia axiomática del capital no opera nunca en forma pura o completamente abstracta. Por el contrario, repone -bajo su propia égida- una serie de formas territorializadas y codificadas (vinculadas al Urstaat y al Edipo) que constriñen y limitan a la producción deseante. De este modo, la disolución de los procesos de territorialización y codificación de flujos en el capitalismo es doblemente limitada: por un lado, por la propia máquina abstracta del capital; por el otro, por las formas de reterritorialización y codificación de flujos gestadas bajo la propia máquina.

En resumen, Postone y Deleuze y Guattari desarrollan poderosas teorías filosóficas que analizan la tensión entre las tendencias disolventes desatadas por el capitalismo, y las constricciones estructurales y sistemáticas puestas por esta forma social históricamente determinada. El capital parece descomponer dimensiones significativas de las formas sociales tradicionales, habilitando una transformación social de peso. Por el otro, esa transformación es reconducida a los goznes formales de la valorización, lo que constriñe el movimiento social en una nueva lógica de tipo abstracto. Este movimiento dual del capital, que fluidifica y a la vez unilateraliza la dinámica social, es analizado por Deleuze y Guattari en términos de axiomática abstracta, y por Postone en términos de mediación social impersonal y anónima.

Existe cierto número de lecturas del pensamiento de Deleuze y Guattari que asocian su filosofía a la celebración del neoliberalismo, la desregulación financiera y la libre circulación de capitales. El ejemplo más paradigmático es Slavoj Žižek, que califica a Deleuze como "el ideólogo del capitalismo tardío" (184). ${ }^{2}$ Para Žižek, el llamado a acelerar la desterritorialización profundizaría las tendencias a multiplicar diferencias del capital, constituyendo una vía muerta para la crítica. Por su parte, Isabelle Garo ha formulado un cuestionamiento

2 A lo largo del artículo, todas las citas de originales en inglés o francés son de traducción propia. 
afín en relación a la "micropolítica" propulsada por Deleuze y Foucault, a la que considera como un intento no conducente por salir de la "alternativa comunista" (35).

Existen, a la vez, algunos estudios importantes sobre la lectura de Marx y el capitalismo que impregna El Anti-Edipo. El más importante es, probablemente, Deleuze, Marx and Politics de Nicholas Thoburn, que a su vez reconstruye largamente la recepción de Deleuze en la tradición operaista italiana. Algunos trabajos como el de Alliez han enfatizado la importancia de la lectura de Marx por parte de Deleuze (sabemos que, cuando murió, trabajaba en un libro titulado Grandeza de Marx). Otro tanto puede decirse de las lecturas de Holland o Mengue, que destacan la afinidad entre el capitalismo y la desterritorialización de los flujos que atraviesan el socius. Asimismo, trabajos como los de Patton o Nail analizan la política deleuziana en el marco de una teoría del capitalismo. Sin embargo, ninguna de estas aproximaciones pone en discusión las analogías entre El Anti-Edipo y las nuevas lecturas de Marx centradas en la reconstrucción de la forma valor, de entre las cuales el pensamiento de Postone es una expresión importante.

Postone, por su parte, ha discutido con el posestructuralismo en algunas ocasiones. Se ha ocupado en términos amplios del "posmodernismo" en "History and Helplessness" y en History and Heteronomy. La indeterminación y la contingencia, sostiene, deberían ponerse como una meta social para ampliar los horizontes democráticos en un mundo poscapitalista. El pensamiento posestructuralista, sin embargo, presentaría a la contingencia como una determinación "ontológica" de toda sociedad posible, constituyendo "[...] una respuesta reificada a una comprensión reificada de la necesidad histórica" (Postone, "History and Helplessness" 95). Los posestructuralistas están en lo correcto al denunciar la pérdida de libertad acarreada por la totalidad, enfatizando en la interrelación entre libertad y contingencia. Sin embargo, se equivocan al hipostatizar ontológicamente la contingencia, ignorando las limitaciones sistemáticas que la dinámica del capital impone a la acción humana.

La superación del capitalismo, entonces, implicaría la abolición de "constricciones estructurales sobre la acción" y la ampliación del "reino de la contingencia y el horizonte de la política" (Postone, "History and Helplessness" 94). El autor defiende la necesidad de un concepto fuerte de la totalidad social como categoría central para comprender la dominación capitalista. Sus 
embates son contra el "posmodernismo" que parecen referirse, sobre todo, al posmarxismo de Ernesto Laclau y Chantal Mouffe. Sin embargo, no ha dedicado trabajos a Deleuze o Guattari, que no son siquiera mencionados en Tiempo, trabajo y dominación social.

Ahora bien, en El Anti-Edipo es posible encontrar una reconstrucción teórica de estas constricciones sistemáticas puestas por el capital, analizadas en términos de axiomática formal y reterritorializaciones. Postone, al totalizar a un conjunto heterogéneo de pensadores bajo la categoría de "posestructuralismo", pasa por alto la teoría del capital desplegada en El Anti-Edipo.

Las interpretaciones y lecturas de Postone producidas hasta el momento abarcan defensas marxistas de la centralidad del proletariado para la crítica del capitalismo (Albriton, Bonefeld), cuestionamientos a su reconstrucción del vínculo entre lógica e historia (Fracchia, Miller, Jay, Arthur) o bien debates sobre su apropiación de Hegel y la dialéctica (McNally). La recepción en castellano de Postone se concentra, por su parte, en algunas pocas publicaciones, que podrían encuadrarse en términos generales en continuidad con las críticas de Bonefeld o Arthur (véase Stoeltzer, Fuentes Maguiña). Estos lectores, entusiastas con varias dimensiones del planteo de Postone, objetan que su noción de totalidad sería demasiado densa y por lo tanto impenetrable por la acción, obturando la construcción de una perspectiva crítica superadora. En síntesis, la bibliografía secundaria en torno a Postone cuestiona su lectura de la lucha de clases, discute su teoría de las abstracciones sociales capitalistas u objeta su construcción del vínculo entre lógica e historia. Con todo, las recepciones críticas de Postone no se han centrado en su relación con el posestructuralismo en general, o con las tesis El Anti-Edipo en particular.

Desde esta perspectiva, voy a estructurar el artículo en tres grandes movimientos. En las primeras dos secciones voy a reconstruir la dominación social abstracta en el capitalismo caracterizado por Postone, así como las potencialidades emancipatorias puestas por el propio capital. En las secciones, tercera, cuarta y quinta, voy a reponer el análisis de la axiomática capitalista en Deleuze y Guattari, recuperando su llamado a desterritorializar y decodificar los flujos más allá de los límites del capital. En la sexta sección desarrollaré una recapitulación comparativa de los análisis previos, señalando las continuidades entre estos autores, así como las diferencias entre ellos. La tesis del artículo es que existe una analogía significativa entre los conceptos de axiomática 
capitalista de Deleuze y Guattari con el de dominación abstracta de Postone, conceptos que dan cuenta de un mismo proceso histórico, aunque lo hagan mediante marcos categoriales diferentes. Los tres autores, asimismo, despliegan una crítica inmanente de la dominación del capital, donde se contrastan formas opresivas y potencialidades emancipatorias.

\section{Postone: capitalismo y dominación abstracta}

Postone reinterpreta el pensamiento de Marx como una comprehensiva teoría crítica de la sociedad moderna en su conjunto, que no se detiene exclusivamente en el conflicto entre clases, sino que analiza de manera global las formas de producción y las maneras en que están estructuradas las relaciones entre las personas. Según esta reinterpretación, con el surgimiento del capitalismo y las relaciones mediadas por el trabajo, se dio una transformación de envergadura en la factura misma del ser social, cambiando cualitativamente la manera como están estructuradas las relaciones entre las personas.

En las sociedades no organizadas a partir del intercambio universal de mercancías, las relaciones sociales son "abiertas" o "manifiestas" [overt], configurando una matriz de relaciones sociales donde la tradición o las decisiones conscientes organizan el trabajo humano. Esto significa que los vínculos sociales aparecen inmediatamente como relaciones entre personas o grupos de personas dados. El trabajo, en ese contexto, no es la categoría que estructura el vínculo social sino que es estructurado por relaciones de otro tipo (fundamentalmente, relaciones de dependencia directa entre individuos o grupos):

Esto [la dominación abstracta del capitalismo] es bastante diferente de las formaciones sociales en las que la producción y el intercambio de mercancías no predominan, donde la distribución social del trabajo y sus productos es efectuada mediante una amplia variedad de costumbres, lazos tradicionales, relaciones abiertas de poder o, posiblemente, decisiones conscientes. El trabajo es distribuido por relaciones sociales manifiestas en las sociedades no capitalistas (Postone, Time, Labor 149-150).

Las relaciones en las sociedades no capitalistas son, según Postone, fundamentalmente abiertas porque aparecen como lo que son: como relaciones 
manifiestas entre personas o grupos. Lazos de autoridad inmediata o de dominación personal, en ese marco, estructuran el vínculo social y distribuyen el trabajo. Con la transición al capitalismo, esas relaciones abiertas o directamente sociales tienden a retroceder, dando lugar a un sistema de compulsiones cuasi-objetivas, fundadas en el trabajo mismo, que ahora pasan a organizar la mediación social. La forma capitalista, históricamente determinada, del trabajo, lo convierte en la categoría fundamental de la dominación social en la modernidad. La interacción social en el capitalismo es atravesada por el valor, la mercancía y el trabajo. Los sujetos particulares no gobiernan el movimiento social del valor, sino que este se gobierna a sí mismo. En otros términos, el trabajo capitalista, expresado en valor y mercancías, es el elemento mediador de la sociedad capitalista. En el capitalismo, el trabajo y sus productos se miden a sí mismos [self-mediating]. Así, las relaciones sociales adquieren el peculiar carácter de pseudo-objetividad, que se enfrenta a las personas como un poder ajeno, inapelable. La crítica del capitalismo, entonces, es la crítica del trabajo como mediador social autonomizado de los sujetos. La forma capitalista de trabajo es objeto (y no sujeto) de tal crítica.

Las relaciones sociales constituidas por el trabajo configuran una dominación social abstracta, impersonal y anónima, que no aparece como social, y no se estructura desde relaciones inmediatas entre las personas. El fetichismo de la mercancía supone que las propiedades sociales de las cosas aparecen como propiedades naturales, no gestadas socialmente. Las mercancías solo poseen valor como una propiedad social, esto es, en la medida en que están insertas en un sistema de intercambio generalizado, donde las personas producen en forma privada, pero lo hacen para el mercado y no para el autoconsumo o la subsistencia.

$\mathrm{Si}$ en las sociedades tradicionales la dominación social se basa en relaciones de dependencia personal, en el capitalismo es la propia factura cuasiobjetiva y abstracta del nexo social fundado en el trabajo la que constituye la dominación. "La dominación social en el capitalismo no consiste, en este nivel fundamental, en la dominación de la gente por otra gente sino en la dominación de la gente por estructuras sociales abstractas que la misma gente constituye" (Postone, Time, Labor 30). La forma de trabajo en el capitalismo, como trabajo dividido en concreto y abstracto, socava las capacidades de las personas para autodeterminarse. Las relaciones abiertas de las sociedades no capitalistas existentes hasta el momento implicaron muchas veces brutales formas de autoridad directa y dominación personal. En el capitalismo, esas 
formas "inmediatas" de dominación tienden a verse desplazadas, pasando a primar la mediación anónima, abstracta y cuasi-objetiva, fundada en el trabajo y el valor. Bajo esa nueva forma de mediación social, las personas pierden capacidad para controlar o modificar conscientemente sus vidas, su trabajo y su producción: "[...] las personas en última instancia no controlan su actividad productiva sino que son dominadas por los resultados de esa actividad" (Postone, Time, Labor 30).

De esta manera, el trabajo constituye una serie de formas sociales mediadoras que no aparecen abiertamente como sociales, que despliegan una dinámica inmanente automática, incontrolable para las personas, que garantiza la dominación social. La crítica del capitalismo, por lo tanto, no es una crítica de la propiedad privada y del mercado desde el punto de vista del trabajo; sino una crítica del trabajo capitalista como sustancia del valor y, por ende, como categoría mediadora fundamental de la sociedad moderna constituida, que crea una lógica de dominación abstracta, impersonal y cuasi-objetiva.

Postone, en resumen, analiza el movimiento dual del capital con respecto a las sociedades abiertas. Por un lado, las formas de dominación personal amparadas en la matriz de relaciones sociales tradicionales son disueltas por el capital, que sitúa a los particulares como individuos independientes, libres e iguales. Por otra parte, la mediación social es ahora asumida por el propio capital, apareciendo como impersonal, anónima y abstracta. Esta nueva forma de mediación, basada en la disolución de los lazos tradicionales, tiene un sujeto global que organiza su dinámica (el capital), cuyo movimiento es automático y reificado. El capital, entonces, restringe el movimiento de lo social, pero ya no sobre bases sustantivas (como en la matriz tradicional de relaciones sociales) sino a partir del movimiento puramente abstracto de sus propias categorías mediadoras, fundamentalmente a partir del movimiento de auto-valorización del valor.

\section{Las potencialidades emancipatorias de la modernidad}

El pensamiento de Postone puede reconstruirse como una crítica global y radical de la modernidad que impugna las formas sociales fundamentales de la sociedad capitalista. Su planteo no se dirige a circunstancias de opresión 
particulares en el seno de una sociedad moderna, sino a las categorías mediadoras de esa sociedad como tales. La modernidad del capital constituye en sí misma una nueva forma de dominación, fundada en las dinámicas impersonales, abstractas y cuasi-objetivas del trabajo como mediador social. Es la forma de mediación característica de la modernidad capitalista la que se estructura en términos de dominación a partir de las categorías fetichizadas del valor, el trabajo y la mercancía. Sin embargo, la crítica de Postone es inmanente a la propia lógica del capital. Las categorías sociales modernas generan, sobre la base de su movimiento reificado, potencialidades emancipatorias capaces de trascender al capitalismo.

La automediación del trabajo en el capitalismo produce la contradicción entre riqueza y valor. Esta da al capital su dinámica característica y hace posible una crítica social inmanente. "Una reinterpretación categorial debe, por tanto, centrarse en la distinción de Marx entre valor y riqueza material" (Postone, Time, Labor 123). El valor "resulta constituido por el gasto de trabajo humano directo en el proceso de producción" al tiempo que "expresa aquello que es, y permanece como, el fundamento básico de la producción capitalista" (Postone, Time, Labor 25). El valor atraviesa toda la mediación social capitalista y también es una forma históricamente determinada de la riqueza, generada a partir del tiempo de trabajo abstracto. Así, la dinámica temporal automática y contradictoria del capital está condicionada por él: "[...] surge una creciente tensión entre este fundamento del modo de producción capitalista y los resultados de su propio desarrollo histórico" (Postone, Time, Labor 25).

El capital posee una dialéctica temporal de transformación y restitución del tiempo de trabajo. Por un lado, incrementa constantemente la productividad. La "hora de trabajo social" se vuelve cada vez más "densa" en términos de la cantidad de mercancías producidas. A la vez, esas transformaciones no llevan a incrementos permanentes en el valor total creado. El valor, al fin y al cabo, depende del tiempo de trabajo empleado y no de su productividad: "[...] aunque un incremento en la productividad genera más riqueza material, el nuevo nivel de productividad, una vez generalizado, produce la misma cantidad de valor por unidad de tiempo" (Postone, Time, Labor 288). La dinámica del capital incrementa la productividad del trabajo, pero no la creación de valor, haciendo que el volumen total de bienes producidos aumente continuamente, sin verse acompañado de un incremento del valor total creado. 
La dialéctica de transformación y restitución de la hora de trabajo, ineluctable y conforme el funcionamiento del valor, vuelve al capitalismo cada vez más anacrónica con respecto a sí misma. El trabajo directo se torna cada vez menos relevante en la producción. En cambio, los poderes socialmente generales de la ciencia y la técnica adquieren primacía. El capitalismo "[...] no solo eleva enormemente la productividad del trabajo, sino que lo hace hasta el punto de tornar la producción de riqueza material esencialmente independiente del gasto inmediato de tiempo de trabajo humano" (Postone, Time, Labor 339).

La generación de riqueza y la de valor entran en contradicción. La producción capitalista, "como proceso de creación de riqueza material, deja de depender necesariamente del trabajo humano directo; empero, como proceso de valorización, permanece necesariamente basada en tal trabajo" (Postone, Time, Labor 342). Esta contradicción creciente da al capitalismo su dinámica histórica característica, en cuyo marco el desarrollo del capital entra en una discrepancia creciente con sus propias bases sociales, históricas y lógicas. Si el trabajo es el fundamento tanto del valor como de la forma de mediación social en el capitalismo, la dinámica temporal desplegada por esta sociedad tiende a reducir la necesidad de trabajo e incrementar la masa de riqueza con independencia del valor producido.

Para Postone, la teoría crítica de la sociedad debe permanecer adecuada a su objeto. No parte de una normatividad formal sino de un "«deber ser» [ought] que emerge como posibilidad histórica inmanente al «es»" (Postone, Time, Labor 89). La "adecuada crítica negativa" parte de lo que podría llegar a ser "como un potencial inmanente a lo que es" (90). El despliegue de la riqueza material podría desaherrojar posibilidades emancipatorias contenidas, pero bloqueadas, en la sociedad capitalista. Esas potencialidades trascendentes son comprendidas, siguiendo a Marx, en términos del "individuo social".

Con el análisis de la contradicción entre riqueza y valor es posible retomar el proyecto de la teoría crítica como crítica social inmanente de la modernidad, que analiza la contradicción entre las formas de dominación existentes y las posibilidades liberadoras gestadas en el interior de esas mismas formas. La teoría, así, es adecuada a su objeto, la sociedad existente, en tanto es a la vez opresiva (estructurada en condiciones de dominación) y generativa (pone las condiciones de posibilidad de su eventual superación). 


\section{Deleuze y Guattari: axiomática y decodificación de flujos}

A continuación intentaréestudiar cómolaaxiomática del capitaldesterritorializa y decodifica los flujos, pero somete todo el movimiento a su dinámica formal. En seguida, trataremos de reconstruir las posibilidades liberadoras abiertas por esa dinámica, que podrían ir más allá de la máquina capitalista abstracta, a partir de un juego de fuerzas inmanente.

Deleuze y Guattari reconstruyen lo que llaman la máquina capitalista civilizada, fundamentalmente, en el capítulo 3 de El Anti-Edipo, sumando algunas otras referencias en otros puntos del texto y también algunas aclaraciones de las clases recuperadas en Derrames. Los autores diferencian tres grandes máquinas históricas que organizan el registro de flujos sobre el socius: la territorial, la despótica y la capitalista. La primera organiza la inscripción sobre el cuerpo completo de la tierra, organizando los flujos por códigos de alianza y filiación. La segunda, levantada junto con el Urstaat, sobrecodifica los flujos que discurren sobre un socius organizado en torno al cuerpo del tirano. El capital, en cambio, se funda por primera vez en una generalizada desterritorialización y decodificación de los flujos. Habilita (en condiciones bien precisas) un movimiento cabalmente formal de las inscripciones sobre el socius, organizadas en torno a una axiomática abstracta que no es, precisamente, un código más. La máquina capitalista es diferente de las anteriores, "se encuentra en una situación totalmente nueva: la decodificación y desterritorialización de los flujos" (Deleuze y Guattari 41).

En un principio, el capital decodifica los flujos de dinero y trabajo (habilita la circulación libre de dinero en multiplicidad de formas e instituye la figura del trabajador libre, no atado por lazos de dominación directa). En esa medida, desterritorializa también los flujos de trabajo, en cuanto presupone la libre movilidad geográfica de los trabajadores. Con esta transformación, el capitalismo bloquea la posibilidad de que un código determinado organice todo el campo social. Tiende a abolir todas las formas determinadas de inscripción de los flujos sobre el socius, desplazando a los códigos y poniendo en su lugar una axiomática abstracta que lo fluidifica todo. "El socius capitalista opera como una 'máquina abstracta' siempre mutando" (Thoburn 90), que es fundamentalmente distinta de las máquinas precapitalistas (despóticas o primitivas). 
El capital tiende al límite esquizofrénico de todo lo social. A toda la realidad subyace una producción deseante que no tiene metas determinadas ni pertenece a un sujeto. En ese sentido, la producción deseante esquizofreniza, en cuanto deviene sin detenerse en una identidad ni meta fija. El capitalismo guarda una relación específica con la producción deseante porque en cierto sentido la desaherroja enormemente, en comparación con las máquinas territoriales y despóticas previas. "El capitalismo tiende hacia un umbral de decodificación que deshace el socius en provecho del cuerpo sin órganos y que, sobre este cuerpo, desencadena los flujos del deseo en un campo decodificado" (Deleuze y Guattari 41). Se produce entonces una enorme carga esquizo: la sociedad "[...] tiende con todas sus fuerzas a producir al esquizo como el sujeto de los flujos decodificados sobre el cuerpo sin órganos" (Deleuze y Guattari 41), que luego el propio capital debe reprimir; restituyendo secundariamente territorialidades y códigos propios de la modernidad (estados, naciones, familias); y citando a todas las formas de codificación previas (la ideología capitalista es "una pintura abigarrada de todo lo que se haya creído jamás” (Deleuze y Guattari 42)).

El capitalismo surge por el encuentro contingente, singular e interactivo entre procesos de decodificación y desterritorialización de flujos con orígenes independientes. "Deseos decodificados y deseos de decodificación, los hubo siempre" (Deleuze y Guattari 265). Lo que da paso al capitalismo es el encuentro preciso entre ciertos flujos decodificados, cuya unidad en cierto momento se genera de modo contingente. Ninguna necesidad histórica gobierna su alumbramiento, dado fundamentalmente por el encuentro contingente entre flujos de trabajadores desterritorializados y dinero decodificado.

En el corazón de El capital, Marx señala el encuentro de dos elementos «principales»: de un lado, el trabajador desterritorializado, devenido trabajador libre y desnudo, teniendo que vender su fuerza de trabajo; del otro lado, el dinero decodificado, devenido capital y capaz de comprar esa fuerza de trabajo (Deleuze y Guattari 266).

El trabajo libre, desligado de las ataduras tradicionales, a la tierra y al señor, por ende desterritorializado, se encuentra contingentemente con el dinero liberado de las codificaciones antiguas, convertido en capital. Este encuentro habilita una decodificación masiva de flujos: reorganización de los medios de 
producción bajo la lógica del capital, pérdida de medios de consumo de los trabajadores por la disolución de la familia y la corporación, decodificación del propio trabajador por la introducción de máquinas en la producción, desterritorialización de la riqueza por la abstracción monetaria, decodificación de los flujos de producción por el capital mercantil, decodificación del Estado por el capital financiero, decodificación de los medios de producción por el capital industrial (Deleuze y Guattari 267). El capital disuelve todas las formas tradicionales y heredadas de organización de la producción, instituyendo un movimiento fluido y sin bordes de cuerpos trabajadores, dinero, medios de producción, etc. "La inscripción comercial y monetaria permanece sobrecodificada e incluso reprimida por las características y los modos de inscripción previos de un socius considerado bajo su modo de producción específico, que no conoce y no reconoce al trabajo abstracto" (Deleuze y Guattari 269).

El capital mantiene una relación compleja con las demás sociedades, la esquizofrenia y sus propios límites. Es "el límite exterior de todas las sociedades" (Deleuze y Guattari 274): todas ellas lo presienten y conjuran porque son asediadas por la producción deseante y su esquizofrenia. Al mismo tiempo, el capital se pone como su propio límite interior, limitando los flujos decodificados que desata y sometiéndolos a su propia axiomática formal. Por eso, el capital esquizofreniza, pero lo hace de manera acotada, precisa, selectiva y limitada.

En síntesis, el capitalismo rompe las codificaciones de flujos antiguas (territorial y despótica), reemplazándolas por su propia axiomática formal y abstracta. En ese movimiento doble, se pone como límite exterior de todas las sociedades anteriores (que conjuran la decodificación de flujos por todos sus medios). A la vez, el capitalismo tiene un límite interno en su propia axiomática, que no puede romper sin desorganizarse y entrar en crisis. Al decodificar los flujos y abrir el socius a la producción deseante, esquizofreniza y se acerca a su propio límite, que desplaza una y otra vez hacia afuera. El esquizo es, entonces, el límite absoluto del capital, su tendencia más íntima y más disolvente, a la que tiende continuamente y que no deja de expulsar y conjurar, evitar y producir, en un acercamiento asintótico a la disolución completa, que el propio capital no puede consumar. 


\section{Reterritorializaciones capitalistas}

Los códigos tradicionales, sin embargo, son reconstituidos en el capitalismo en la forma de arcaísmos sociales refuncionalizados. La axiomática formal no trabaja en el vacío: necesita codificaciones que le garanticen la continuidad y subsistencia (Deleuze y Guattari 276). La producción deseante es sometida al tamiz edípico en las específicas condiciones del capitalismo. Bajo el imperio de las máquinas territorial y despótica, “[...] la reproducción económica no es jamás independiente de la reproducción humana” (Deleuze y Guattari 313). No existe entonces la familia en el sentido nuclear y privativo que adquiere en la modernidad, sino que esta es "una praxis abierta, una estrategia coextensiva al cuerpo social" (Deleuze y Guattari 313). Las relaciones de parentesco organizan directamente la producción social en las sociedades precapitalistas.

En ese marco, no existe una esfera económica separada de otras actividades sociales. Esta autonomización entre la economía y los lazos de parentesco surge propiamente con el capitalismo, habilitando a la vez la lógica del capital como valor que se auto-valoriza y la "privatización de la familia" (Deleuze y Guattari 313). La familia nuclear, separada de la reproducción social y económica, constituida como esfera de intimidad, es entonces un resultado de la dinámica social más amplia del capitalismo. A partir de la privatización de la familia como unidad de consumo, antes que de producción, se genera la colonización edípica del sujeto en virtud de la cual "cada uno tiene sus propios madre y padre privados" (Deleuze y Guattari 315). Edipo viene entonces a poner coto a las posibilidades abiertas que la decodificación capitalista, de otra manera, haría fluir de modo abierto. "El triángulo edípico es la territorialidad personal y privada que se corresponde con todos los esfuerzos de reterritorialización del capitalismo" (Deleuze y Guattari 317). La constitución de la sexualidad edípica, encerrada en la triangulación familiar, es la contracara general de la axiomática del capital.

La reterritorialización edípica de la sexualidad y del deseo es fundamental porque funda las disyunciones exclusivas que organizan otras reterritorializaciones importantes. "Edipo es un medio de integración en el grupo" (Deleuze y Guattari 123). Las identificaciones edípicas entre padre, jefe $\mathrm{y}$ otras figuras de autoridad favorecen la constitución de formas segregativas de lo social. Estas formas no coinciden con la división en clases, por lo que se crean modos de pertenencia segregativos que refuerzan identificaciones autoritarias, reaccionarias, etc. Las formas segregativas de investidura libidinal 
producen exclusiones violentas de grupos subyugados, reforzando el poder del propio capital. El Edipo se anuda con ellas, constituyendo su salvaguardia en cada individuo. "Edipo depende de esta clase de sentimiento nacionalista, religioso, racista, y no al revés: no es el padre el que es proyectado sobre el jefe, sino el jefe el que se aplica sobre el padre" (Deleuze y Guattari 123). Las reterritorializaciones racistas, nacionalistas, que refuerzan a la axiomática del capital, son entonces articuladoras del Edipo, que funciona como instancia de refuerzo de todas ellas.

La segunda gran reterritorialización capitalista es el estado moderno, que cita el Urstaat arcaico formulado bajo las condiciones especiales y diferentes de la axiomática del capital. Reconociendo que el estado moderno es un "verdadero corte" en comparación con el despótico (Deleuze y Guattari 310), los autores no dejan de ver en esta institución una repetición (en condiciones nuevas) del Urstaat arcaico. Esta repetición capitalista del estado permite las reterritorializaciones necesarias para que la axiomática del capital no conduzca a la disolución del socius. "La paradoja es que el capitalismo hace uso del Urstaat para efectuar sus reterritorializaciones" (Deleuze y Guattari 311). En este sentido, "el capitalismo nunca ha sido liberal, siempre ha sido capitalismo de Estado” (Deleuze 45).

Latemporalidaddinámicadela modernidades, porloanterior, oscilante(Deleuze y Guattari 311). De una parte, hay cargas paranoicas, edípicas y segregativas, que refuerzan al estado y la familia, y producen identificaciones de grupo violentas y excluyentes. Del otro lado, la producción deseante esquizofrenizando, discurriendo por flujos desterriotiralizados y decodificacdos. La axiomática moderna bascula entre dos polos: la desterritorialización general de los flujos y su reterritorialización por las regresiones fascistas al Urstaat, la figura paterna y la autoridad constituida edípicamente. "Nacidas de la decodificación y la desterritorialización, sobre las ruinas de la máquina despótica, estas sociedades están atrapadas entre el Urstaat que querrían resucitar [...] y los flujos desencadenados que entran en un umbral absoluto" (Deleuze y Guattari 309). En resumen, el capital no se limita a desterritorializar y decodificar para poner una axiomática formal a cambio. Por el contrario, bajo el imperio de su axiomática, produce poderosos movimientos de reterritorialización muy fuertes, orientados a la construcción de investiduras segregativas y fundados en el Edipo y el Urstaat. En el límite, estas investiduras segregativas conducen al fascismo como posibilidad íntima de la modernidad del capital. 


\section{Acelerar la decodificación y la desterritorialización: capitalismo y esquizofrenia}

¿Qué horizonte emancipatorio se dibuja en El Anti-Edipo? ¿Cuáles son los procesos que podrían llevar más allá de la axiomática capitalista y sus tendencias reterritorializantes? Las posibilidades de un más allá del capitalismo se dibujan a partir de los movimientos de la producción deseante y la esquizofrenia como movimiento decodificado de los flujos. Deleuze y Guattari reconstruyen la posibilidad de trascender el capitalismo sobre la base de sus propias tendencias inmanentes, que este debe arrestar continuamente para garantizarse continuidad. La decodificación y la desterritorialización de los flujos, habilitadas por el propio capital, abren entonces la posibilidad de un más allá poscapitalista.

Pero, ¿cuál es la vía revolucionaria? ¿Existe una? ¿Separarse del mercado mundial? [...] ¿ $\mathrm{O}$ podría ser ir en la dirección opuesta? ¿Ir más lejos en el movimiento del mercado, de la decodificación y la desterritorialización? Porque tal vez los flujos no están todavía lo bastante desterritorializados ni lo bastante decodificados, desde el punto de vista de una teoría y una práctica de un flujo esquizo de alto grado. No retirarse del proceso, sino ir más lejos, «acelerar el proceso» como dijo Nietzsche: en verdad, en este punto, todavía no hemos visto nada (Deleuze y Guattari 285).

Acelerar el proceso esquizofrénico abierto por el capitalismo hasta llevarlo a sobrepujar sus límites. Porque, con la desterritorialización y la decodificación de flujos, el capital puso al descubierto una verdad histórico-universal: la producción deseante como tal, que esquizofreniza todas las formas determinadas de codificación y axiomatización.

Con el capitalismo se ponen en la dinámica social dos grandes abstracciones que habilitan un gran dinamismo: la riqueza abstracta y la libido abstracta. "Tantas razones para definir el capitalismo por una axiomática social que se opone a los códigos en todo respecto. Ante todo, el dinero como equivalente general representa una cantidad abstracta que es indiferente a la naturaleza cualificada de los flujos" (Deleuze y Guattari 295-296). La abstracción dineraria decodifica porque los códigos particulares, determinados, le son indiferentes. La circulación del dinero 
como capital, a su vez, presupone una decodificación masiva que permita al dinero reconvertirse en un movimiento constante (D-M-D) y sin límite.

Luego, el capital presupone la abstracción dineraria como instancia de decodificación general del socius y, en particular, de la riqueza. La libido subjetiva abstracta es, de igual modo, descubierta por el capital. Si la economía política (que solo pudo construirse en el capitalismo) se basa en la riqueza subjetiva abstracta, de igual modo el psicoanálisis se basa en "la libido subjetiva universal" (Deleuze y Guattari 360). Ambas son descubiertas por el capitalismo, cuyo proceso de desterritorialización descubre propiamente la "actividad de la producción en general y sin distinción" (Deleuze y Guattari 360). Al descubrir la libido y la riqueza abstractas, el capitalismo vislumbra un principio ontológico del socius como tal, y de la producción deseante en su generalidad multiforme y decodificada.

El esquizo, sin embargo, permanece como el límite exterior del capital. Es su tendencia íntima y su imposibilidad constitutiva. El capital no puede permitir el despliegue de los flujos decodificados sin someterlos a un doble régimen de axiomática y de reterriotorializaciones. Al tiempo que aparece como límite relativo de las demás sociedades, la capitalista encuentra en la esquizofrenia su propio límite exterior y absoluto. He ahí la barrera que no puede superar: decodifica los flujos, pero solo hasta un punto, solo en ciertas condiciones determinadas y precisas, solo de cierta manera y bajo sus propios límites. Lo disuelve todo, menos a su propia axiomática formal, que a su vez nunca puede funcionar sola sino que instituye perpetuamente nuevas territorializaciones. El más allá del capitalismo se dibuja sobre la base del desencadenamiento de la producción deseante más allá de este doble movimiento que la arresta, primero axiomáticamente, luego reterritorializándola.

\section{Comparación y conclusiones}

A continuación trazaré algunas comparaciones entre Tiempo, trabajo y dominación socialyElAnti-Edipo. En ambostextos, el capitalismo escaracterizado por una forma de dominación abstracta, que se diferencia cualitativamente de las formas de dominación precapitalistas y funda una especificidad histórica. 
Para Postone, el capitalismo tiende a desplazar las relaciones sociales abiertas e instituir en su lugar al trabajo como categoría social mediadora. Las relaciones sociales abiertas son aquellas que aparecen como tales, como vínculos de dependencia entre personas y grupos. Es manifiesto, entonces, que una relación social entre personas organiza el vínculo social. Este tipo de formas sociales no son mediadas por el trabajo. En cambio, en su seno el propio trabajo es una categoría mediada, inserta en una matriz de relaciones organizada por la tradición, por formas políticas de dominación, etc.

Esa matriz de relaciones abiertas es desarticulada por el capital, que en cambio pone una forma social anónima, impersonal y abstracta. Ya no son relaciones de dominación manifiestas las que organizan la mediación social. Ahora esta es articulada por el intercambio de trabajo y sus productos. El trabajo se convierte en categoría social mediadora y estructura el vínculo social, que se vuelve abstracto y cuasi-objetivo. La vida social pasa a tomar la forma de un cúmulo de compulsiones abstractas, cuyo sujeto es la producción de valor o la reproducción del capital. El capitalismo, por lo tanto, rompe las formas tradicionales de dominación, pero instaura en su lugar una nueva dominación social, solo que de carácter abstracto e impersonal. Su surgimiento presupone la disolución de todas las formas particulares y determinadas de dominación basadas en relaciones personales de dependencia, al tiempo que instituye una nueva dinámica de dominación fundada de carácter anónimo y abstracto.

De modo análogo a lo descrito arriba, para Deleuze y Guattari, la especificidad histórica del capitalismo está dada por la construcción de una axiomática abstracta que reemplaza la codificación de flujos. Bajo las máquinas territoriales o despóticas, los flujos de la producción deseante son codificados y territorializados, lo que supone una inscripción cualitativamente determinada de su dinamismo. En el capitalismo se rompen las formas previas de territorialización y codificación de flujos. La axiomática (cuya premisa fundamental es la valorización del valor) es formal: admite una pluralidad de códigos, lo que permite al capitalismo citar contenidos varios de la historia universal y ponerlos a trabajar en su interior. Esta flexibilidad con respecto a los códigos implica que ninguno de ellos es, en principio, estructurante del socius en el capitalismo, que se ve decodificado como tal. Luego, la abstracción capitalista aparece como límite exterior de toda sociedad. Sin embargo, inmediatamente el capitalismo limita o arresta la producción deseante, 
poniendo ahora a su propia axiomática como límite. De ahí que el capital sea el límite solo relativo, pero no absoluto, de lo social: esquizofreniza o abre la producción, pero solo hasta un punto. En el límite, debe volver a contener los flujos que pondrían en riesgo su propia axiomática.

Puede derivarse de lo anterior una segunda analogía. Los tres pensadores estudiados rompen con las filosofías especulativas de la historia, incluido el materialismo histórico. No intentan construir una teoría general de la sucesión de las épocas humanas en la que el capitalismo sería una fase necesaria. Por el contrario, consideran que el surgimiento del capitalismo es un fenómeno singular y contingente, no dado por necesidad transhistórica alguna. La conjunción de elementos que dio lugar al capitalismo es producto del encuentro de procesos disímiles coordinados de modo no necesario. La historia universal es, en las dos obras analizadas, una mirada retrospectiva lanzada desde la sociedad capitalista hacia el pasado: solo desde el punto de vista del capital se transparenta algo como la historia universal. Luego, la idea misma de una continuidad histórica gobernada por un sujeto o una necesidad general tiene un anclaje perspectivo en la crítica del capital.

Hay también una tercera analogía significativa entre Postone y Deleuze y Guattari: en ambos casos la crítica del capital tiene bases inmanentes. Esto significa que cuestionan la dominación en el capitalismo a partir de dinámicas abiertas por él mismo. En el caso de Postone, la contradicción entre riqueza y valor es puesta por el capital, al tiempo que apunta a su superación posible. La lógica del capital impone sobre la producción la compulsión a acumular, constituyendo una forma de dominación ciega e impersonal. Bajo esa lógica ciega, los capitales se ven forzados a introducir permanentemente tecnología ahorradora de trabajo en la producción con el fin de obtener plusvalor extraordinario e incrementar sus ganancias.

Como resultado de todo el proceso, el trabajo humano directo (fundamento de la creación de valor) pasa a ser cada vez menos importante en la producción de riqueza material. La sociedad produce cada vez más riqueza, pero no más valor. $\mathrm{Al}$ mismo tiempo, las fuerzas sociales generales de la ciencia y la técnica se convierten en los factores de producción principales, desplazando al trabajo directo. Esta dinámica genera una contradicción creciente entre las potencialidades creadas por el capital y su propia forma histórica. El capital 
como sociedad mediada por el trabajo se vuelve anacrónico con respecto de sus resultados históricos, en cuanto, en virtud de su propia lógica, torna al trabajo cada vez menos importante en la producción. La crítica del capital se basa, por lo tanto, en la discrepancia creciente entre las potencialidades sociales y técnicas puestas por el propio capitalismo y su forma social constituida.

Deleuze y Guattari, por su parte, proponen acelerar o profundizar los procesos de decodificación y desterritorialización de flujos abiertos por el capital. Si el capital esquizofreniza (desaherroja la producción deseante), el problema es que no esquizofreniza lo bastante. El capital, como vengo sosteniendo, arresta la producción deseante al tiempo que la abre. Por una parte, al desplazar a la máquina despótica, decodifica masivamente los flujos del socius. Por la otra, reemplaza los códigos por su axiomática, al tiempo que instituye codificaciones y territorializaciones nuevas bajo su propia égida. Ante esta dinámica dual del capital, la crítica de los autores no se dirige a sus tendencias esquizo sino a las instancias en que el capital limita la producción deseante; precisamente, la axiomática, las reterritorializaciones y nuevas codificaciones estatales o edípicas. Se trata, por lo tanto, de una crítica inmanente del capital en cuanto cuestiona sus formas de represión del deseo desde el punto de vista de procesos desterritorializados y de decodificación, abiertos parcialmente sobre la base del propio capital. La apuesta es entonces acelerar la decodificación y la desterritorialización de flujos, abriendo la producción deseante más allá de las constricciones impuestas por capital y su axiomática.

Sintetizando, en este trabajo intenté un estudio comparativo de las teorías del capitalismo de Postone en Tiempo, trabajo y dominación social y Deleuze y Guattari en El Anti-Edipo. Sostuve que los tres autores presentan teorías históricamente determinadas del capitalismo, que rompen con las filosofías especulativas de la historia universal y despliegan la crítica del capital en términos inmanentes. Estas analogías dan cuenta de una caracterización común del capitalismo, producida desde matrices diferentes, pero centrada en la especificidad histórica y la crítica inmanente. En efecto, en ambos libros, el capitalismo aparece como una forma social específica, cuyas dinámicas sociales no son reductibles a las de las sociedades previas.

El capitalismo, en efecto, decodifica y desterritorializa los flujos o disuelve las relaciones sociales abiertas para instituir en una axiomática o una dominación 
abstracta. Su surgimiento es en ambos libros considerado como una ocurrencia contingente, que no viene exigida por una necesidad histórica preexistente. Finalmente, en ambos casos, la crítica del capital tiene bases inmanentes. En el caso de Postone, se funda en la contradicción entre las potencialidades creadas por el capitalismo y su realidad actual como forma de dominación. En el caso de Deleuze y Guattari, en la posibilidad de profundizar los procesos de desterritorialización y decodificación hasta llevarlos más allá de la axiomática abstracta. El cuestionamiento filosófico de la dominación del capital es posible, entonces, gracias a las dinámicas transformadoras abiertas bajo el imperio de esa propia dominación.

\section{Referencias}

Alliez, Ėmmanuel. "Questionnaire on Deleuze". Theory, Culture and Society 14.2 (1997): 81-87.

Albritton, Robert. “Theorizing Capital's Deep Structure and the Transformation of Capitalism”. Historical Materialism 12.3 (2004): 72-94.

Arthur, Chris. "Review of Time, Labor and Social Domination". Capital and Class 54 (1994): 150-153.

Bonefeld, Werner. "On Postone's Courageous but unsuccesful attempt to banish the class antagonism from the critique of political economy". Historical Materialism 13.3 (2004): 113-124.

Deleuze, Gilles. Derrames. Entre el capitalismo y la esquizofrenia. Buenos Aires: Anagrama, 2006.

Deleuze, Gilles y Guattari, Felix. L’Anti-Oedipe. Capitalisme et Schizophrénie. Paris: Editions de Minuit, 1972.

Dhruv Jain. (ed.). Deleuze and Marx. Deleuze Studies. Vol. 3. Edimburgo: Edinburgh University Press, 2009.

Fracchia, Joseph. "On Historical Abstractions and the Intersection of Historical Theory and Social Critique". Historical Materialism 12.3 (2004): 125-146.

Fuentes Maguiña, Antonio. "Contradicción, antagonismo y agencia. Inquietudes alrededor de Postone”. Bajo el volcán 9.15 (2010): 169-181.

García Vela, Alfonso. “Trabajo concreto y valor de uso ¿Ontología o especificidad histórica”. Revista herramienta s/n (2011). Recuperado de: https://herramienta. com.ar/articulo.php?id=1505

Garo, Isabelle. “Foucault, Deleuze, Althusser \& Marx, la política en la filosofía”. Ideas de Izquierda 5 (2013): pp. 33-35. 
Holland, Eugene. Deleuze, Guattari and Minor Marxism. 2013. Recuperado en: http:// works.bepress.com/eugene_w_holland/3/

Jay, Martin. “Marx after Marxism”. New German Critique 60 (1993): pp. 181-191.

Mcnally, David. "The Dual Form of Labour in Capitalist Society and the Struggle for Meaning”. Historical Materialism 12.3 (2004): 189-211.

Mengue, Philippe. Deleuze o el sistema de lo múltiple. Buenos Aires: Las cuarenta, 2008.

Patton, Paul. "What is Deleuzian Political Philosophy?". Revista de Teoría Politica 1 (2011): 115-126.

Nail, Thomas. Returning to Revolution. Deleuze, Guattari and Zapatismo. Edinburgo: Edinburgh University Press, 2012.

Postone, Moishe. Time, Labor and Social Domination. A reinterpretation of Marx's Critical Theory. Cambridge: Cambridge Uniersity, 1993.

Postone, Moishe. "History and Helplessness". Public Culture 18.1 (2006): 93-110.

Postone, Moishe. History and heteronomy. Critical Essays. Tokio: UTCP, 2009.

Stoetzler, Marcel. "El Marx de Postone. Un teórico de la sociedad moderna, los movimientos sociales de ésta y su aprisionamiento por el trabajo abstracto". Bajo el volcán 9.15 (2010): 139-168.

Thoburn, Nicholas. Deleuze, Marx and Politics. Londres: Routledge, 2003.

Žižek, Slavoj. Organs Without Bodies. Deleuze and Consequences. Londres: Routledge, 2003. 